\title{
Knowledge, practice and factors associated with poor compliance with universal precautions among healthcare workers at Bugando Medical Centre, Mwanza, Tanzania
}

\author{
GETRUDE CHALYA 1 , FIDELIS MBUNDA² and PHILLIPO L. CHALYA ${ }^{*}$ \\ ${ }^{1}$ Department of Community Medicine, Catholic University of Health and Allied Sciences-Bugando, Mwanza, \\ Tanzania \\ ${ }^{2}$ Department of Surgery, Catholic University of Health and Allied Sciences-Bugando, Mwanza, Tanzania
}

\begin{abstract}
Background: Healthcare workers (HCWs) are exposed to blood-borne infections by pathogens, such as HIV, and Hepatitis B and C viruses, as they perform their clinical activities in hospitals. Compliance with universal precautions has been shown to reduce the risk of exposure to these pathogens. This aimed at assessing the knowledge, practices and factors associated with poor compliance to universal precautions among HCWs at Bugando Medical Centre in Mwanza, Tanzania.

Methods: This was a cross sectional study carried out from December 2014 to February 2015.

Results: There were 200 participants including 62 (31.0\%) doctors, 74 (37.0\%) nurses, laboratory personnel $34(17.0 \%)$ and $29(14.5 \%)$ auxiliary HCWs. More than three quarters (82\%) of participants had adequate knowledge of universal precautions. There was statistically significant difference between knowledge of universal precautions and sex, job category, working experience ( $\geq 5$ years) and previous training on universal precautions. Out of $200 \mathrm{HCWs}, 154$ (77.0\%) practiced universal precautions. Working experience ( $\geq 5$ years) and previous training on universal precautions were significantly associated with good practice of universal precautions $(\mathrm{P}<0.001)$. There was a strong correlation between knowledge and compliance (practice) with universal precautions $(r=0.76, p<0.001)$. Factors associated with poor compliance with universal precautions included lack of personal protection equipment (69.5\%), lack of knowledge (65.0\%), emergency situations (63.0\%), presumption that patient is not infected with HIV or HBV (59.0\%), time constraints (53.0\%), heavy workload (48.0\%) and absence of penalties (34.0\%).

Conclusion: There was adequate knowledge and a fair level of compliance among HCWs towards universal precautions. These findings suggest that training of health care workers to increase their knowledge about blood-borne pathogens and universal precautions could improve their compliance and thus reduce health care workers' risk of blood-borne pathogen exposure.
\end{abstract}

Keywords: universal precautions, knowledge, practice, factors, poor compliance, hospital, Tanzania

\section{Introduction}

Health care workers, as they perform their clinical activities, are at risk of various occupational hazards in the hospital, including exposure to blood-borne infections such as HIV and hepatitis B and $\mathrm{C}$ virus (HBV and HCV) from sharps injuries and contact with body fluids (Gerberding, 1994; Mizumo et al., 1997; Beltrami et al., 2000; Shias et al., 2002). Developing countries, which account for the highest prevalence of HIV-infected patients in the world, also record the highest rate occupational infections including needle-stick injuries (Shias et al., 2002; Pruss-Üstün et al., 2003). The World Health Organization (WHO, 2002) estimates that about $2.5 \%$ of HIV cases and $40 \%$ of HBV and HCV cases among HCWs worldwide are the result of these exposures. The risk of seroconversion following a needle-stick injury from an $\mathrm{HCV}$-antigen-positive patient is estimated to range from $1.2 \%$ to $10 \%$ (McCarthy, 2000) and, as there is no immunization currently available for HIV and HCV infection. It is therefore, important to prevent infection by preventing exposure to infection.

Since identification of patients infected with blood-borne pathogens cannot be reliably made by medical history and physical examination, the Centers for Disease Control and Prevention

\footnotetext{
${ }^{*}$ Correspondence E-mail: drphillipoleo@yahoo.com
} 
(CDC) have recommended universal precautions to help protect both healthcare workers and patients from infection with blood-borne pathogens in the healthcare setting (CDC, 1996). Universal precautions are simple infection prevention control measures that reduce the risk of transmission of blood-borne pathogens through exposure to blood and body fluids among patients and HCWs (Chan et al., 2002). Under universal precautions principles, blood and certain body fluids of all patients are considered potentially infectious of blood borne pathogens, regardless of actual infectiousness (McCarthy, 2000; Chan et al., 2002: Lynch et al., 2007). Compliance with these universal precautions has been shown to reduce the risk of exposure to blood and body fluids (Lynch et al., 2007).

Despite evidence that failure to use universal precautions increases the risk of blood-borne infections such as HIV, HBV and HCV, poor compliance with universal precautions among healthcare workers practicing in developing countries has been extensively reported (Askarian et al., 2005: Kuzu et al., 2005; Thu et al., 2012). Gershon et al. (1995) observed that better knowledge of universal precautions among healthcare workers was one of the correlates of good compliance. The level of compliance with universal precautions by healthcare workers may differ from one type of healthcare workers to another. The differences in knowledge of universal precautions by healthcare workers may be influenced by their varying type of training (Lynch et al., 2007). The absence of an enabling environment in the health institution, such as a lack of constant running water or a shortage of personal protective equipment (PPE), would lead to poor compliance with universal precautions. It, therefore, becomes important to assess the level of compliance with universal precautions by the various types of HCWs who make direct contact with patients, and level of compliance by HCWs in the various types of health facilities (Amoran \& Onwube, 2013). The knowledge and compliance with universal precautions among HCWs at Bugando Medical Centre has not been assessed before. This study aimed at assessing the knowledge and level of compliance with universal precautions and identifies factors associated with poor compliance to universal precautions among HCWs at Bugando Medical Centre, in north-western Tanzania.

\section{Materials and Methods}

\section{Study design and setting}

This was a cross sectional study to assess the knowledge, practice and factors associated with poor compliance universal precautions among healthcare workers at Bugando Medical Centre over a 3month period from December 2014 to February 2015. The study was conducted at Bugando Medical Centre. Bugando Medical Centre is a tertiary care and teaching hospital for the Catholic University of Health and Allied Sciences-Bugando (CUHAS-Bugando) and it is located in Mwanza City in the north-western part of Tanzania. It is situated along the shore of Lake Victoria and has about 1,000 beds and over 1,200 employees. BMC is one of the four largest referral hospitals in the country and serves as a referral centre for tertiary specialist care for a catchment population of approximately 13 million people from neighbouring regions

\section{Study population}

The study included all health-care workers who come into contact with patients, or who are potentially exposed to body fluids from patients while attending to or handling samples from patients. Health care workers were included in the study if they had full-time employment at Bugando Medical Centre. Only those who were present at the time of data collection were recruited. The workers whose jobs are not directly related to health care delivery services and handling of injections were excluded from this study. Health care workers were also excluded from the study if they were unable to be present at a study site at the appointed time because they had to attend an emergency. Health care workers who did not complete the questionnaire were not included in the final data analysis. 
Purposive sampling was used for selecting the wards and in each selected ward a list of names for the HCWs was obtained from the team leader. Simple random sampling was then applied to obtain eligible participants. All the eligible participants were selected and those who consented to participate were recruited into the study. Independent variables of interest were age, sex, job category, professional qualification, working place, working experience and previous training on universal precaution. The dependent (outcome) variable was compliance with universal precaution.

\section{Data collection}

Data were collected using a self-administered semi-structured questionnaire that was designed to assess the health workers' knowledge and compliance on universal precautions. The questionnaire consisted of 4 sections that included: (i) items regarding participants' characteristics information; (ii) 10 - items regarding knowledge; five items regarding practice (compliance); and five items regarding factors associated with poor compliance. The questionnaire administration took about 20 minutes to complete.

The knowledge of universal precautions was measured by examining ten questions regarding universal precautions. A score of " 1 " for a correct answer and " 0 " for an incorrect answer was assigned. The total score ranged from 0 to 10. A healthcare worker who obtained a total score of " $5-10$ " was considered to have "adequate knowledge;" and those who obtained a total score of " $<5$ " was considered to have "inadequate knowledge". The compliance (practice) with universal precautions was measured using a self-reported practice (compliance) on universal precautions. A score of 2 was given to HCWs with the responses "always", a score of 1 and o were given in HCWs with the responses "occasionally" and "never", respectively. The total score ranged from 0 to 10. We defined "good practice "among HCWs who obtained a score of 5-10 and "poor practice" among those who obtained a score $<5$.

\section{Data analysis}

Data was analysed using SPSS software version 17.0. Means, median, mode and standard deviation were used to summarize continuous variables. Chi-square test was used to test for significance of associations between the predictor and outcome variables in the categorical variables. Student $t-$ test was used to test for significance of associations between the predictor and outcome variables in the continuous variables. Significance was defined as a p-value of less than 0.05 . Multivariate logistic regression analysis was used to determine predictor variables that are associated with outcome

\section{Ethical considerations}

Ethical approval to conduct the study was obtained from the Joint Institutional Ethic Review Committee of the Catholic University of Health and Allied Sciences and Bugando Medical Centre. The study participants were asked to choose to participate voluntarily after getting clear message using a special informed consent form. Study participants were assured of confidentiality, privacy and harmony before participating.

\section{Results}

\section{Participants' characteristics}

Out of the 208 healthcare workers recruited, 200 fully completed the questionnaire, giving a response rate of $96.2 \%$. Among them 114 (57.0\%) were males and $86(43.0 \%)$ were females with a male to female ratio of 1.3: 1. The age of participants ranged from 21 to 62 years with a median age of 36 years (interquartile range, 32-38 years). The modal age group of participants was 30-39 years accounting for $37.0 \%$. Of the HCWs surveyed, there were 62 (31.0\%) doctors, 74 (37.0\%) nurses, laboratory personnel $34(17.0 \%)$ and 29 (14.5\%) auxiliary HCWs. Regarding professional 
qualifications, 81 (40.5\%) participants had university degrees, 55 (27.5\%) had diplomas, 38 (19.0\%) had certificates and the remaining $26(13.0 \%)$ had other qualifications. Most HCWs were working in the laboratories (18.0\%). Other working places were medical wards (16.0\%), Operating theatre (14.0\%), obstetrics/gynaecology wards (12.5\%), A\&E department (11.5\%), surgical wards (10.5\%), paediatric wards (9.0\%), and others (8.5\%). Most participants, $128(64.0 \%)$ had less than five years. The majority of participants, 134 (67.0\%) had attended educational or training courses on universal precautions.

\section{Knowledge regarding universal precautions}

The majority of HCWs, $174(87.0 \%)$ were aware of the concept of universal precautions. Out of the $174 \mathrm{HCWs}$, seminar/workshop was the commonest source of information accounting for 83 (41.5\%) of them. The media, classroom lectures and other sources accounted for $25.0 \%, 20.0 \%$ and $13.5 \%$, respectively. Table 1 shows distribution of HCW's knowledge regarding universal precautions.

Table 1: Distribution of HCW's knowledge regarding universal precautions

\begin{tabular}{|c|c|c|c|}
\hline \multirow[b]{2}{*}{ No } & \multirow[b]{2}{*}{ Items } & \multicolumn{2}{|c|}{ Frequency $\mid \%$} \\
\hline & & True & False \\
\hline 1. & $\begin{array}{l}\text { Universal precautions are applied to patients with HIV and viral } \\
\text { hepatitis only (F) }\end{array}$ & $52(24.0)$ & $148(74.0)$ \\
\hline 2. & Isolation is necessary for patients with blood-borne infections (F) & $76(38.0)$ & $124(62.0)$ \\
\hline 3 & Used needles can be recapped after giving an injections (F) & $78(39.0)$ & $122(61.0)$ \\
\hline 4 & $\begin{array}{l}\text { For decontamination of devices (with only contact with skin) washing } \\
\text { with usual detergent is enough }(F)\end{array}$ & $73(36.5)$ & $127(63.0)$ \\
\hline 5. & $\begin{array}{l}\text { Universal precautions are not necessary in situations that might lead } \\
\text { to contact with saliva (F) }\end{array}$ & $52(26.0)$ & $148(74.0)$ \\
\hline 6. & $\begin{array}{l}\text { HCWs with non-intact skin should not be involved in direct patient } \\
\text { care until the condition resolves }(\mathrm{T})\end{array}$ & $102(51.0)$ & $98(49.0)$ \\
\hline 7. & $\begin{array}{l}\text { Subcutaneous injuries during intravenous injections are the most } \\
\text { common cause of occupational infections (T) }\end{array}$ & $108(54.0)$ & $92(46.0)$ \\
\hline 8. & $\begin{array}{l}\text { Blood spills should be cleaned up promptly with sodium hypochlorite } \\
\text { (T) }\end{array}$ & $114(57.0)$ & $86(43.0)$ \\
\hline 9. & $\begin{array}{l}\text { The used needles should be disposed into a sharps box after } \\
\text { injection.(T) }\end{array}$ & $152(76.0)$ & $48(24.0)$ \\
\hline 10. & $\begin{array}{l}\text { Masks and goggles are necessary if procedures and patient-care } \\
\text { activities are likely to cause splashing of blood or exposure to deep } \\
\text { body fluids }(\mathrm{T})\end{array}$ & $174(87.0)$ & $26(13.0)$ \\
\hline
\end{tabular}

Note: The correct answer is stated in brackets next to the questions ( $T=$ True, $F=$ False)

According to the HCW's knowledge assessment tool regarding universal precautions (Table 2), the majority of patients, $164(82.0 \%)$ had adequate knowledge whereas 36(18.0\%) had inadequate knowledge.

Table 2: HCW's knowledge assessment tool regarding universal precautions

\begin{tabular}{|c|c|c|}
\hline Items & Response & Score \\
\hline \multirow{2}{*}{ Universal precautions are applied to patients with HIV and viral hepatitis only (F) } & Correct & 1 \\
\hline & Incorrect & 0 \\
\hline \multirow[t]{2}{*}{ Isolation is necessary for patients with blood-borne infections (F) } & Correct & 1 \\
\hline & Incorrect & 0 \\
\hline \multirow[t]{2}{*}{ Used needles can be recapped after giving an injections (F) } & Correct & 1 \\
\hline & Incorrect & 0 \\
\hline \multirow{2}{*}{$\begin{array}{l}\text { For decontamination of devices (with only contact with skin) washing with usual } \\
\text { detergent is enough (F) }\end{array}$} & Correct & 1 \\
\hline & Incorrect & 0 \\
\hline
\end{tabular}


Universal precautions are not necessary in situations that might lead to contact with saliva (F)

HCWs with non-intact skin should not be involved in direct patient care until the condition resolves $(\mathrm{T})$

Subcutaneous injuries during intravenous injections are the most common cause of occupational infections (T)

Blood spills should be cleaned up promptly with sodium hypochlorite (T)

The used needles should be disposed into a sharps box after injection.(T)

Masks and goggles are necessary if procedures and patient-care activities are likely to cause splashing of blood or exposure to deep body fluids ( $T$ )

Total

Note: The correct answer is stated in brackets next to the questions ( $T=$ True, $F=$ False)

Interpretation: A score of 5-10 = adequate knowledge, a score $<5=$ inadequate knowledge

Results of multivariate logistic regression analysis showed statistically significant difference between knowledge of universal precautions and (i) sex: the knowledge of universal precautions was significantly high among females (94.7\%) than men (65.1\%) ( $P=0.012)$; (ii) Job category: more nurses (94.7\%), medical doctors (90.3\%) and laboratory technologists (82.4\%) were very knowledgeable of universal precautions compared with only 31.0\% of auxiliary HCWs $(P<0.0001)$; (iii) Working experience: health care workers employed for a period of five years and more (97.2\%) were more knowledgeable than those who served for less than five years $(73.4 \%)(P=0.002)$; and (iv) Previous training on Universal Precautions: HCWs who had previous training on universal precautions (98.5\%) were very knowledgeable than those who had no previous training (48.5\%) (Table3).

Table 3: Factors associated with knowledge of universal precautions among HCWs at BMC: Results of univariate and multivariate logistic regression analysis

\begin{tabular}{|c|c|c|c|c|c|}
\hline \multirow{2}{*}{$\begin{array}{l}\text { Independent (predictor) } \\
\text { variable }\end{array}$} & \multicolumn{2}{|c|}{ Knowledge (N’\%) } & \multirow{2}{*}{$\begin{array}{l}\text { Univariate analysis } \\
\text { OR , } 95 \% \mathrm{Cl} \text {, P-value }\end{array}$} & \multirow{2}{*}{\multicolumn{2}{|c|}{$\begin{array}{l}\text { Multivariate analysis } \\
\text { OR , } 95 \% \mathrm{CI} \text {, P-value }\end{array}$}} \\
\hline & Adequate & Inadequate & & & \\
\hline \multicolumn{6}{|l|}{ Age (in years) } \\
\hline - $\quad<40$ & $112(82.4)$ & $24(17.6)$ & & & \\
\hline - $\quad \geq 40$ & $52(81.3)$ & $12(18.7)$ & $2.3(0.3-6.4) 0.965$ & & \\
\hline \multicolumn{6}{|l|}{ Sex } \\
\hline - Male & $108(94.7)$ & $6(5 \cdot 3)$ & & & \\
\hline - Female & $56(65.1)$ & $30(34.9)$ & $4.9(2.8-7.8) 0.015$ & $8.3(4 \cdot 5-10.8)$ & 0.002 \\
\hline \multicolumn{6}{|l|}{ Job category } \\
\hline - Doctors & $56(90.3)$ & $6(9.7)$ & & & \\
\hline - Nurses & $71(94.7)$ & $4(5 \cdot 3)$ & $1.8(1.2-5.1) \quad 0.011$ & $3.9(2.2-8.3)$ & 0.026 \\
\hline $\begin{array}{l}\text { - Laboratory } \\
\text { personnel }\end{array}$ & $28(82.4)$ & $6(9.7)$ & $4.9(2.9-11.8) 0.023$ & $2.1(11-6.2)$ & 0.032 \\
\hline $\begin{array}{c}\bullet \quad \text { Auxiliary HCWs } \\
\text { Working experience (year }\end{array}$ & $9(31.0)$ & $20(69.0)$ & \multicolumn{2}{|c|}{ Working experience (years) } & 0.001 \\
\hline - $\quad<5$ & $94(73.4)$ & $34(26.6)$ & & & \\
\hline - $\quad \geq 5$ & $70(97.2)$ & $2(2.8)$ & $3.2(1.1-7.5) \quad 0.004$ & $4.3(1.3-6.9)$ & 0.021 \\
\hline \multicolumn{6}{|c|}{$\begin{array}{l}\text { Previous training on universal } \\
\text { precautions }\end{array}$} \\
\hline - Yes & $134(98.5)$ & $2(2.5)$ & & & \\
\hline
\end{tabular}




\begin{tabular}{lllllll}
\hline- No & $32(48.5)$ & $34(51.5)$ & $6.2(3.7-9.7)$ & 0.002 & $2.9(1.1-6.8)$, & 0.001
\end{tabular}

Keys: $\mathrm{OR}=$ Odds ratio, $\mathrm{Cl}=$ confidence interval

\section{Compliance (practice) with universal precautions}

The use of double gloves had the highest degree of compliance (91.5\%) while recapping needles after use (27.5\%) had the lowest (Table 4 ).

Table 4: Self-reported practice of universal precautions among HCWs at BMC

\begin{tabular}{rlll}
\hline & & \multicolumn{2}{c}{ Response } \\
\cline { 3 - 4 } S/N & Practice of universal precautions & Yes & No \\
\hline 1. & Use of double gloves & $183(91.5)$ & $17(8.5)$ \\
2. & Use of protective eye wear & $178(89.0)$ & $22(11.0)$ \\
3. & Use of protective outer clothing (e.g. apron) & $175(87.5)$ & $25(12.5)$ \\
4. & Use of gum shoes & $170(85.0)$ & $30(15.0)$ \\
5. & Recapping needles after use & $55(27.5)$ & $145(72.5)$ \\
\hline
\end{tabular}

Generally, with regard to HCW's practice/compliance assessment tool for universal precautions (Table 5), of the $200 \mathrm{HCWs,} 154$ (77.0\%) practiced universal precautions and the remaining 46 (23.0\%) were not. According to multivariate logistic regression analysis, working experience $(\geq 5$ years $)(\mathrm{OR}=5.6,95 \% \mathrm{Cl}(2.3-8.9), \mathrm{P}=0.012)$ and previous training on universal precautions $(\mathrm{OR}=1.8$, $95 \% \mathrm{Cl}(1.1-6.3), \mathrm{P}=0.001)$ were significantly associated with good practice of universal precautions.

Table 5: HCW's practice/compliance assessment tool for universal precautions

\begin{tabular}{|c|c|c|}
\hline $\mathbf{S} / \mathbf{N}$ & Practice of universal precautions & Score \\
\hline \multirow[t]{4}{*}{1.} & Use of double gloves & \\
\hline & - Always & 2 \\
\hline & - Occasionally & 1 \\
\hline & - $\quad$ Never & $\mathbf{0}$ \\
\hline \multirow[t]{4}{*}{2.} & Use of protective eye wear & \\
\hline & - Always & 2 \\
\hline & - Occasionally & 1 \\
\hline & - $\quad$ Never & $\mathbf{0}$ \\
\hline \multirow[t]{4}{*}{3.} & Use of protective outer clothing (e.g. apron) & \\
\hline & - Always & 2 \\
\hline & - Occasionally & 1 \\
\hline & - $\quad$ Never & $\mathbf{0}$ \\
\hline \multirow[t]{4}{*}{4.} & Use of gum shoes & \\
\hline & - $\quad$ Always & 2 \\
\hline & - Occasionally & 1 \\
\hline & - Never & 0 \\
\hline \multirow[t]{4}{*}{5 . } & Recapping needles after use & \\
\hline & - $\quad$ Always & 2 \\
\hline & - Occasionally & 1 \\
\hline & - $\quad$ Never & 0 \\
\hline & Total score & 10 \\
\hline
\end{tabular}

Interpretation: A score of 5-10 = good practice/compliance, a score $<5$ =poor practice/compliance

Our findings show that there was a strong correlation between knowledge and compliance (practice) with universal precautions $(r=0.76, p<0.001)$ (i.e. HCWs that had adequate knowledge were more likely to have good practices). 


\section{Factors associated with poor compliance}

The reasons for poor compliance with universal precautions as reported by HCWs are summarized in Table 6. Lack of PPE, lack of knowledge and emergency situations accounted for the most frequently mentioned reasons for poor compliance.

Table 6: Reasons for poor compliance with universal precautions

\begin{tabular}{lll}
\hline Reasons for poor compliance with universal precautions & Frequency & Percentages \\
\hline Lack of personal protection equipment (PPE) & 139 & 69.5 \\
Lack of knowledge & 130 & 65.0 \\
Emergency situations & 126 & 63.0 \\
Presumption that patient is not infected with HIV/HBV & 118 & 59.0 \\
Time constraints & 106 & 53.0 \\
Heavy workload & 96 & 48.0 \\
Absence of penalties & 68 & 34.0 \\
\hline
\end{tabular}

\section{Discussion}

This study found out that the majority of HCWs at Bugando Medical Centre were young in their second and third decades of life and still having many years of productive lives ahead and as such the need to protect them from blood borne pathogens was a serious necessity. This finding is similar to what was obtained in a study done by Jangua et al (2007) in Pakistan where the mean age of the healthcare workers was reported to be 30 years. Most of HCWs in this study were males, a finding which is at variance with other studies which reported female preponderance (Gershon et al., 1995; Thu et al., 2012). We could not establish the reason for this female predominance. In our study, the majority of the HCWs who were interviewed were nurses. This is in agreement with findings of other studies elsewhere (Danchaivijitr et al., 1995; Janjua et al., 2007; Thu et al., 2012). The large proportion of nurses in this study could be explained by the fact that nurses form the largest proportion of HCWs in the hospital.

This study showed that knowledge of universal precautions among healthcare professionals was variable. The majority of the health care workers had knowledge of universal precautions while less than one-fifth had no knowledge. Knowledge of universal precautions was highest among women compared with men, and among nurses, medical doctors and laboratory personnel. The results of this study are in agreement with those of Danchaivijtr et al. (1995) in Thailand who reported that most medical doctors had knowledge of standard precautions. The adequate knowledge of universal precautions among nurses, medical doctors and laboratory personnel may reflect the fact that universal precautions have been incorporated in the nursing, medical and laboratory student's curricula in Tanzanian universities and colleges, and also in onthe-job training protocols at BMC. The low level of understanding of universal precautions among auxiliary HCWs may be attributed to the absence of this information during introductory training courses and orientation programmes. Furthermore, the deficient knowledge base among some of the health care workers may be due to a lack of investment in staff training or to limited understanding of health care workers' safe behaviour in the clinical setting or complacency (Godin et al., 2000). However, it is important to note that due to insufficient information retention, knowledge and adherence to taught practice may still be deficient in spite of training and education (Stein et al., 2003: Wang et al., 2003; Trim et al., 2003).

In this study, health care workers employed for longer periods had adequate knowledge of universal precautions than those who served for shorter periods. Training and education have been found to be of paramount importance to developing awareness among health care workers, as well as improving adherence to good clinical practice (Wang et al., 2003; Kermode et al., 2005). The greater knowledge among health care workers employed for a longer period in this study may reflect their participation in a greater number of training and educational sessions on universal 
precautions which not only encouraged safer work practices but also improved concordance with policy and procedures (Kermode et al., 2005).

Healthcare workers are exposed to a variety of occupational exposures in clinical settings. The transmission of infectious pathogens is a major concern and the best way of preventing acquired infections in healthcare settings is to comply with universal precautions practices and to avoid exposure to blood and other body fluids (Lynch et al., 2007; Thu et al., 2012). In this study, more than three quarters of HCWs practice universal precautions, a figure which is high than that reported in other studies (Kermode et al., 2005; Janjua et al., 2007). The compliance for use of most PPE was high. However, it was lower as regards to recapping of needles. The practice of recapping needles has been identified as a contributor to incidence of needle-stick injuries among HCWs and therefore should be prohibited in the healthcare facilities in line with the Occupational Safety and Health Administration (OSHA) guidelines (Janjua et al., 2007). In the present study, working experience ( $\geq 5$ years) and previous training on universal precautions were significantly associated with good practice of universal precautions. Training and education have been found to be of paramount importance in developing awareness among HCWs as well as improving adherence to good clinical practice (Wang et al., 2003; Kermode et al., 2005). The level of training in terms of universal precautions of the current participants is higher than a finding obtained in a study carried out in India (Madan et al., 2002), in which 36\% HCWs had received training.

In agreement with other studies (Askarian et al., 2005; Kuzu et al., 2005), our findings show that there is a strong correlation between knowledge and compliance (practice) with universal precautions. In this case, HCWs who had adequate knowledge were more likely to have good practice. A study in Iran showed that areas of poor knowledge, such as washing hand before and after using gloves, correlated with poor practices (Kuzu et al., 2005). Compliance with universal precautions has resulted in significant reduction in the endemic level of drug-resistant bacteria in healthcare facilities.

Despite good compliance (practice) with universal precautions in this study, noncompliance among health care workers was reported in less than a quarter of the participants. The reasons for non-compliance with universal precautions as reported by HCWs included lack of PPE, lack of knowledge, emergency situations, presumption that patient is not infected with HIV/HBV, time constraints, heavy workload and absence of penalties. It should be noted that it is the duty and responsibility of the employer to provide personal protective equipment and the appropriate training for the correct use. Furthermore, improvement in safety equipment is needed to better protect health care workers from exposure to blood-borne pathogens (Mastertone et al., 2007). Inadequate knowledge of universal precautions by HCWs has been reported to be associated with poor compliance (Chan et al., 2002; WHO, 2003). This observation is reflected in our study where two thirds of the HCWs reported that lack of knowledge as one of the reasons responsible for the poor compliance with universal precautions. Although universal precautions provide protection from a range of blood-borne pathogens, their effectiveness relies upon the knowledge of HCWs and the level of compliance in their use (Gershon et al., 1995; Chan et al., 2002).

Similar to our findings, a previous study in Vietnam has shown that dealing with an emergency situation is a factor inhibiting HCWs from implementing universal precautions (Thu et al., 2012). Most often, an emergency situation requires doing a lot of things at the same time, very fast and usually under heavy pressure. Osborne (2003) in Australia observed that one of the barriers that influence the compliance with universal precautions was that HCWs perceive that the patient is not infected. This finding concurs with our study in which approximately sixty percent of HCWs do not use any universal precautions because they believed that the patients are not infected and do not pose a risk to them. In terms of time constraints, similar to our findings, a previous study in Tanzania, health care workers reported time restraints as a barrier to implement universal precautions. They reported that due to heavy workload, there is no time to follow universal precautions (Oliveira et al., 2010). Inadequate time has also been widely described 
elsewhere (Henry et al., 1994; Gould et al., 1996; Oliveira et al., 2010) as factor not facilitating the implementation of universal precautions.

Heavy workload has also been reported as a barrier in compliance among health workers. In studies elsewhere, health workers have found difficult to accommodate universal precautions due to day to day current clinical pressures (Henry et al., 1994; Gould et al., 1996). Yet, several studies have shown that lack of penalties for non-compliance with universal precautions is one of the factors associated with poor compliance to universal precautions (Nsubuga \& Jaakkhola, 2005; Tetali \& Choudhry, 2006). This observation is reflected in our study where more than one third of $\mathrm{HCW}$ s reported absence of penalties for non-compliance with universal precautions.

The major limitation of this study was failure to establish cause and effect relationship in view of the cross sectional nature of the study. The study may also be subjected to recall bias. The questionnaire with multiple choices must have prompted HCWs to give their responses from the choices. Hence the possibility of getting average or good score could be a chance factor in this study. This study was also limited by the self-report method of assessment of practice of universal precautions, because the level of compliance might have been more properly assessed by observation. The likely tendency for the HCWs to exaggerate their compliance with universal precautions may have produced a less favourable picture than it actually is. However, despite these limitations, this study provided local data that may help healthcare workers in our setting and in similar institutions in resource limited countries to increase the level of compliance with universal precautions.

In conclusion, this study showed that there is adequate knowledge and a fair level of compliance regarding universal precautions among healthcare workers at Bugando Medical Centre. These findings suggest that training of health care workers to increase their knowledge about blood-borne pathogens and universal precautions could improve their use of universal precautions. Regular training should include the universal precautions, initial biohazard handling, safety policies, safety activities, safety equipment and materials, ongoing monitoring and potential exposure of staff.

\section{References}

Askarian, M., Mirzaei, K., Mundy, L.M. \& McLaws, M.L. (2005) Assessment of knowledge, attitudes and practices regarding isolation precautions among Iranian healthcare workers. Infection Control \& Hospital Epidemiology 26, 105-108.

Beltrami, E.M., Williams, I.T., Shapiro, C.N. \& Chamberland, M.E. (2000) Risk and management of blood-borne infections in health care workers. Clinical Microbiology Reviews 13, 385-407.

CDC (1986) Recommendation for preventing transmission of infection human T-lymphotropic virus type III/lymphadenopathy associated virus during invasive procedure. Morbidity and Mortality Weekly Report 35, 221-223.

Chan, R., Molassiootis, A., Chan, E., Chan, V., Ho, B., Lai, CY., Lam, P., Shit, F. \& Yiu, I. (2000) Nurses' knowledge of and compliance with universal precaution in an acute care hospital. International Journal of Nursing Studies 39, 157-163.

Danchaivijitr, S., Tantiwatanapaiboon, Y., Chokloikaew, S., Tangtrakool, T., Suttisanon, L. \& Chitreechuer, L. (1995) Universal precautions: knowledge, compliance and attitudes of doctors and nurses in Thailand. Journal of the Medical Association of Thailand 78, 112-117.

Gerberding, J.L. (1994) Incidence and prevalence of human immunodeficiency virus, hepatitis B virus, hepatitis $C$ virus, and cytomegalovirus among health care personnel at risk for blood exposure: final report from a longitudinal study. Journal of Infectious Diseases 170, 1410-1417.

Gershon, R.R.M., Vlahov, D., Felknor, S.A., Vesley, D., Johnson, P.C., Delcios, G. L. \& Murphy, L.R. (1995) Compliance with universal precautions among health care workers at three regional hospitals. American Journal of Infection Control 23, 225-236. 
Gould, D., Wilson-Barnett, J. \& Ream, E. (1996) Nurses' infection-control practice hand decontamination, the use of gloves and sharp instruments. International Journal of Nursing Studies 33, 143-160.

Henry, K., Campbell, S., Collier, P. \& Williams, C.O. (1994) Compliance with universal precautions and needle handling and disposal practices among emergency department staff at two community hospitals. American Journal of Infection Control 22, 129-137.

Janjua, N.Z., Razaq, M., Chandir, S., Rozi, S. \& Mahmood, B. (2007) Poor knowledge predictor of nonadherence to universal precautions for blood borne pathogens at first level care facilities in Pakistan. BMC Infectious Diseases 7, 81.

Kuzu, N., Ozer, F., Aydemir, S., Yalcin, A.N. \& Zencir, M. (2005) Compliance with hand hygiene and glove use in a university-affiliated hospital. Infection Control \& Hospital Epidemiology 26, 312-315.

Lynch, P., Pittet, D., Borgc, M.A. \& Mehtard, S. (2007) Infection control in countries with limited resources. Journal of Hospital Infection 65, 148-150.

Masterton, R., Craven, D., Rello, J., Struelens, M., Frimodt-Moller, N. \& Chastre, J. (2007) Hospital acquired pneumonia guidelines in Europe: a review of their status and future development. Journal of Antimicrobial Chemotherapy 60, 206-13

McCarthy, G.M. (2000) Universal Precautions. Journal of the Canadian Dental Association 66, 556557.

Nsubuga, F.M. \& Jaakkola, M.S. (2005) Needle sticks injuries among nurses in sub-Saharan Africa. Tropical Medicine \& International Health 10, 773-781.

Oliveira, A.C., Cardoso, C.S. \& Mascarenhas, D. (2010) Contact precautions in intensive care units: facilitating and inhibiting factors for professionals' adherence. Revista da Escola de Enfermagem - USP 44, 161-165.

Osborne, S. (2003) Influences on compliance with standard precautions among operating room nurses. American Journal of Infection Control 31, 415-423.

Pruss-Üstün, A., Rapiti, E. \& Hutin, Y. (2003) Sharps Injuries: Global Burden of Disease from Sharps Injuries to Health-Care Workers. Environmental burden of disease series No. 3. World Health Organization, Geneva.

Tetali, S. \& Choudhry, P.L. (2006) Occupational exposure to sharps and splash: risk among health care providers in three territory care hospitals in South India. Indian Journal of Occupational and Environmental Medicine 10, 35-40.

Thu, T.A., Anh, N.Q., Chau, N.Q. \& Hung, N.V. (2012) Knowledge, attitude and practices regarding standard and isolation precautions among Vietnamese health care workers: a multicenter cross-sectional survey. Journal of Internal Medicine 2,115. doi:10.4172/21658048.1000115

WHO (2002) The World Health Report 2002: Reducing Risks, Promoting Health Life. World Health Organization, Geneva.

WHO (2003) Safe Injection Global Network. Health Care Workers Safety. Aide-Memoire for a Strategy to Protect Health Care Workers from Infection with Blood Borne Viruses. World Health Organization. WHO/BCT/03.11, 2003. 